\title{
AVALIAÇÃO DA ATENÇÃO EM UMA AMOSTRA DE MOTOCICLISTAS
} ASSESSMENT OF ATTENTION IN A SAMPLE OF MOTORCYCLISTS

DÉBORA SPRENGER 1 ; ELIENE COSTA 2; ANDRÉA BORGES 3 ; FERNANDO PESSOTO $0_{4}$; JOSÉ M. MONTIEL 5 ; DANIEL

BARTHOLOMEU 6 ; DANIEL HEITOR 7 ; LESLIE LITANO TEALDI8

(CENTRO UNIVERSITÁRIO FIEO, Osasco - SP, Brasil)

\begin{abstract}
RESUMO
A pesquisa realizada teve como objetivo comparar alguns aspectos psicológicos de dois grupos sendo motociclistas que se utilizam da motocicleta apenas para lazer e dos motoboys, que se utilizam do meio de transporte principalmente para 0 trabalho. Por meio de instrumentos psicológicos e do questionário WHOQOL, foi avaliado o nível de atenção concentrada e difusa e qualidade de vida dos participantes. A pesquisa contou com 30 participantes, sendo 15 do grupo de motoboys e 15 de motociclistas. Utilizou-se como instrumentos o teste AC (Atenção Concentrada), TADIM (Atenção Difusa) e 0 questionário Whoqol. Observou-se que houve diferença significativa no teste de atenção concentrada, sendo que 0 escore dos motoboys apresentou menor índice que dos motociclistas. Esta diferença pode ser justificada pelo fato do ambiente de trabalho dos motoboys ser composto de diversas contingências.
\end{abstract}

PALAVRAS-CHAVES: Motoboy, avaliação psicológica, acidentes de trânsito.

\section{ABSTRACT}

The research aimed to compare the psychological profile of two groups: motorcyclists that use the motorcycle only for leisure and "motoboys" who use it mainly for work. 30 participants (15 motoboys and 15 motorcyclists) were studied. The instruments were the ACT (Attention Concentration Test); the DAT (Divided Attention Test); and the Whoqol. Results in the ACT show significant differences between motoboys and motorcyclists: the former presenting less incidence of attention concentration than the latter. This difference might be justified by the fact that motoboys' work environment involves more diverse contingencies.

KEY WORDS: Motoboy, psychological assessment, attention, quality. 


\section{INTRODUÇÃO}

De acordo com o Código Brasileiro de Ocupação (Ministério do Trabalho e emprego, 2002) no 5191-10, motoboy é o profissional que desenvolve trabalhos de entrega e transporte, como por exemplo, bens perecíveis, documentos, produtos, remédios, refeições, dentre outros. Para Negri e Lazzarato (2001) o trabalho deste profissional pode se tornar um trabalho imaterial, ou seja, intelectual e corporal caracterizado pela solicitação cada vez mais frequente nos deliverys, pois ao mesmo tempo em que as mercadorias transportadas oferecem certo conforto emocional aos motoboys por se tratarem de produtos intangíveis, a experiência vivenciada por eles envolvendo permanente estado de alerta, causa desgaste físico.

Esta categoria de trabalho surgiu de uma demanda de serviços que exigiam cada vez mais agilidade, praticidade e conforto. Essa situação é presente devido ao crescimento dos centros urbanos, de novas soluções para gerir determinados trabalhos e das novas implicações do modo de viver, como por exemplo, o aumento do fluxo de carros no trânsito. Geralmente os motoboys são do sexo masculino, jovens, provenientes do desemprego e acreditam que uma solução para seus problemas esteja nesse trabalho (Grisci, Scalco \& Tanovik, 2007). A prática da categoria requer uma carga horária extensiva, que os obriga a permanecer à disposição da empresa, o que acaba prejudicando as relações familiares e 0 convívio social. Algumas rupturas se dão devido à esta da disposição constante, 0 que pode causar desencontros com seus familiares. A incerteza de seu retorno também é presente, ocasionando muitas vezes, um clima de apreensão (Negri \& Lazzarato, 2001).

De acordo Bauman (2001) o estilo de vida dos motoboys é caracterizado pelas regras que os impedem de exibir determinados

comportamentos considerados inadequados para a profissão. Estas regras devem ser respeitas à ponto ocorrerem descontos no salário. Frente à isto, a velocidade com que estes profissionais atingem com suas motos se caracteriza pelo objetivo de atender à pressão por produtividade que lhes é imposta, pois aquele que corre mais acaba por receber melhores salários. Portanto, a agilidade e rapidez, que permeia a categoria e a sociedade que exige urgência e velocidade nos serviços prestados, contribuem para a ocorrência de acidentes dos motoboys.

$\begin{array}{rrr}\text { Segundo Honoré (2005), } & \text { estes } \\ \text { profissionais } & \text { desenvolveram um }\end{array}$ relacionamento peculiar com seus pares e com a sociedade em geral, o que causam sentimentos contraditórios de ambas as partes. Diante da não aceitação das barreiras do espaço público na condução dos motoboys, e por serem constantemente indagados pelos agentes do trânsito, acabam reagindo agressivamente ao trânsito. 0 motoboy se tornou 0 personagem mais lembrado das grandes cidades brasileiras, pois é o profissional que resolve os problemas da falta de tempo das pessoas ao mesmo tempo em que colide com os retrovisores dos automóveis e, com suas buzinas, faz lembrar o atraso e a perda de tempo no congestionamento.

Os motoboys reconhecem que são imprudentes no trânsito, e justificam isso pela característica mais cobrada na profissão, a velocidade (Silva e cols., 2008). Embora a Classificação Brasileira das Ocupações ([CBO] Ministério do Trabalho e emprego, 2002) da categoria motoboy não faça menção à velocidade dos mesmos, esta característica é cobrada para os serviços, muitas vezes pelo próprio motoboy e a justificativa pode ser pelo sentido que essa característica oferece a existência da profissão, causando impasse entre estes profissionais (Grisci, Scalco \& Tanovik, 2007). 
Pela crescente cobrança da agilidade, estes profissionais aderiram a truques para reduzir o percurso e diminuir o tempo de entrega do serviço, como evitar ruas com semáforos e lombadas; passar nos cantos destas, mesmo expostos ao risco de queda; andar na contramão; e por fim, não parar em sinais vermelhos. Porém, alguns profissionais expõem algumas vantagens $\mathrm{e}$ desvantagens em pertencer à esta categoria. Dentre as vantagens estão a sensação de liberdade, oportunidade de conhecer novos lugares na cidade, fazer novas amizades, sensação de autonomia em relação a execução das tarefas. Em contrapartida 0 sol excessivo, chuva, desgaste físico e emocional, risco de assalto e grande probabilidade de acidente, são percebidos como negativos (Silva e cols., 2008).

As más condições no trânsito em união à precária condição de trabalho do motoboy, torna essa categoria de profissão muito perigosa. Acidentes com vítima fatal envolvendo motos é maior do que com caminhões (Moraes, 2008). A soma destes fatores acaba por ser um desencadeador de estresse para estes indivíduos, que muitas vezes, dependem desse trabalho para seu sustento. Frankenhaeuser e Gardell, (1976); Kalimo, (1980) e Levi (1988), já salientavam que, em ambientes de trabalho, o estresse caracteriza-se como um desequilíbrio entre as demandas do mesmo e a capacidade de resposta dos trabalhadores.

A Saúde Mental e o Trabalho tem sido alvo de estudos desde a década de 80 . Sato e Bernardo (2005) descrevem que grande parte destes estudos são baseados em atividades de intervenção à partir de serviços públicos de saúde e de entidades sindicais. Dejours (1986, apud Glina e cols., 2001) frisa que as organizações podem exercer efeitos tanto positivos quando negativos, no funcionamento mental do trabalhador devido a divisão de tarefas que englobam 0 modo como todas as tarefas devem ser desempenhadas, coincidindo ou não com o modo de trabalhar do indivíduo. No caso dos motoboys, mesmo estes tendo um local de trabalho fixo onde encontram-se as mercadorias à serem entregues, é no trânsito que passam grande parte de seu horário de trabalho.

O trânsito por sua vez, é composto por três fatores, à saber, o homem, a via e o veículo, sendo todos causadores de acidentes. O homem, considerado fator humano (FH), pode causar acidentes pela ausência de atenção, falta de experiência, excesso de velocidade, consumo de drogas ou álcool e pela transferência de seus próprios problemas para o trânsito. A via, denominada de fatores viário-ambientais (FVA), pela precariedade na sinalização e falta de passarelas, buracos, semáforos com defeitos e outros. O veículo, denominado fatores veiculares (FV), por falta de manutenção. Mesmo sendo fatores separados, muitas vezes apresentam interações, podendo ser dois ou até mesmo os três, os fatores causadores de um acidente (Rozestraten, 1988).

A via caracteriza-se como um caminho, uma guia que conduz algo de um lugar para outro e deve seguir padrões exigidos por órgãos destinados a essa finalidade. Muitas delas não os seguem, são mal conservadas e deixadas em segundo plano, e muitas vezes, a justificativa destes desajustes é que 0 homem as utiliza de forma inadequada causando-os, podendo este ser 0 motivo de acidentes (Brasil, 2007). De acordo com Cereser (2007), o homem vê a via como o palco no qual se desenrola 0 drama do trânsito, ou seja, todo ambiente que rodeia o veículo ou o pedestre, no qual ambos se movimentam. Sendo assim, torna-se necessário uma correspondência entre as condições da via e as necessidades do usuário, como por exemplo, uma rua com buracos pode irritar - motorista e requerer uma atenção redobrada do mesmo. 
Explanando ainda sobre o fator via, outros elementos podem ser causadores de acidentes como os ambientais, à saber, chuva, neblina, nevoeiro, ventos fortes, entre outros. A chuva, por exemplo, caracteriza-se como um fator ambiental causador de acidente devido à redução de visibilidade e, caso o pavimento não tiver um sistema de drenagem adequado, irá criar piscinas de água na superfície fazendo com que os veículos percam a aderência do asfalto, ocasionando assim, acidentes (Brasil, 1994).

Inseridos nas vias, encontram-se os veículos, que segundo Cereser (2007) é o espelho daquele que o conduz e é nessa forma que a pessoa revela seu grau de satisfação ou insatisfação com a vida, ou seja, quanto mais potente e bonito 0 automóvel, mais poderoso o condutor se sente. Uma pessoa que vive bem ajustada na sociedade pode se comportar melhor no trânsito. Em outros termos, atitudes positivas como cordialidade, respeito ao espaço do outro, dentre outras, trazem benefícios para 0 trânsito. 0 contrário a essas atitudes podem, ocasionar problemas devido ao caráter coletivo e muitas vezes, competitivo do trânsito.

De acordo com 0 Departamento Nacional de Trânsito (Brasil, 2009) uma questão importante referente ao veículo é sua a boa condição de conservação, pois aqueles que apresentam defeitos se tornam mais difíceis de serem dirigidos e controlados em uma situação de perigo. Um fator considerado importante referente à preservação é a regulagem dos faróis, pois quando desregulados podem atrapalhar uma boa condução ofuscando a visão do motorista quando um carro estiver vindo em direção contrária, por exemplo. Os dois fatores citados anteriormente estão diretamente ligados ao terceiro, que é considerado o maior causador de acidentes de trânsito, afinal, os dois sofrem influência direta deste. Um bom motorista precisa ter suas habilidades psicomotoras adequadas para manobrar com destreza um veículo bem como controlar suas emoções e ter consciência que o trânsito é um ato coletivo e não individual (Cereser, 2007).

Sabey e Staughton (1975) apontam que $79,3 \%$ dos acidentes de trânsito são decorrentes de falha humana ou atitudes inadequadas. A agressividade e a irresponsabilidade são fatores de risco mais frequentemente geradores de acidentes. As condições e o estado emocional podem afetar negativamente a habilidade de processar as informações para que os motoristas dirijam com segurança. Os autores complementam que sentimentos como a raiva, estresse, ansiedade, agressividade e angústia muitas vezes estão relacionados à personalidade do indivíduo e afetam a atitude do motorista ao dirigir, aumentando assim a probabilidade de ocorrência de acidentes.

Segundo os apontamentos e determinações da Resolução 80 do CONTRAN, muitos desses fatores podem ser mensurados por meio do exame psicotécnico. Este tem por objetivo avaliar psicometricamente as áreas perceptoreacional, equilíbrio psíquico e habilidade específica e complementar, por meio de técnicas psicológicas como entrevistas e ainda observação durante a realização dos exames. A área percepto-reacional e motora está relacionada à atenção, percepção, tomada de decisão, motricidade e reação, cognição e nível mental dos condutores. A de equilíbrio psíquico relaciona-se com a ansiedade e excitabilidade, ausência de quadro reconhecidamente patológico, controle adequado da agressividade e impulsividade, equilíbrio emocional, ajustamento pessoal-social e problemas correlatos como alcoolismo, epilepsia, uso de droga, entre outros, que possam detectar contraindicações à segurança do trânsito. Por fim a área de habilidade específica e complementar diz respeito ao tempo de reação, atenção concentrada, rapidez de raciocínio e relações espaciais. 
Em seu estudo Orsati e colaboradores (2004) descrevem que os acidentes no trânsito não ocorrem por fatalidades, na maioria das vezes, predominam as falhas humanas envolvendo os construtos psicológicos descritos anteriormente. Segundo Hoffmann (2005) existem vários estudos a fim de modelar o comportamento do condutor (Botticher \& Van der Molen, 1988; Michon, 1989; Summala, 1988), Tais comportamentos são distinguidos em três níveis, à saber, o operacional, que consiste num plano de viagem, a rota, uma previsão dos custos que serão gerados pela viagem e os riscos que a compõe; o tático, em que - condutor controla as manobras que podem ser realizadas, como obedecer sinalizações de trânsito, e até mesmo evitar alguns obstáculos; o terceiro que engloba 0 controle sob o veículo é o operacional, sendo um exemplo dele o controle da velocidade.

É possivel observar que falhas podem ocorrer nos três níveis. Brouwer, Rothengatter e Van Wolffelaar (1988), Machado (1994), Rozestraten (1993) salientam que a atenção concentrada e distribuída geralmente oferece problemas à pessoas mais velhas ou em condutores sobre pressão do fator tempo, comprometendo assim o desempenho do indivíduo ao dirigir. Ao lado disso, Panichi e Wagner (2006) salientam que a busca por sensações intensas, agressividade, hostilidade, impulsividade, labilidade emocional, locus de controle, comportamento delinquente e motivação antisocial são alguns dos fatores de personalidade relacionados ao envolvimento em acidentes de trânsito.

A atenção relaciona-se à percepção, sendo considerada uma qualidade desta e ainda enquadra-se como imprescindível para o motorista no momento da condução do veículo. Quando bem desenvolvida, pode auxiliar em tomadas de decisões mais adequadas e assertivas no surgimento de eventos como, por exemplo, desviar de pedestres que atravessam a rua fora da faixa, veículos em fila dupla ou ainda qualquer outro estímulo que pode aparecer em fração de segundos (Tonglet, 2002). 0 condutor, para evitar acidentes, necessita manter sua atenção no trânsito observando não apenas a sinalização como também 0 movimento dos pedestres e dos outros veículos. Quando se estuda os princípios da direção defensiva, observa-se que o método básico de prevenção de acidentes consiste em três ações interligadas sendo elas, prever o perigo, descobrir o que fazer e agir a tempo. Sendo assim, para que o condutor seja capaz de prever o perigo, é necessário que esteja atento aos estímulos que estão à sua volta (Cereser, 2007).

Estudos realizados por Tonglet (2002) apresentam três tipos de atenção, a concentrada, a discriminativa e a difusa, avaliadas durante o processo para obtenção e/ou renovação da carteira nacional de habilitação tanto para condutores de veículos automotores como para motociclistas. Entende-se por atenção concentrada a focalização dos interesses de um indivíduo em um único estímulo ou um grupo deles que apresentam características em comum. Já a atenção difusa envolve 0 processo no qual 0 indivíduo focaliza de uma só vez diversos estímulos localizados em diferentes pontos. Por fim, a atenção discriminativa é a capacidade de focalizar vários estímulos diferentes e selecionar somente 0 aquele ou aqueles de maior interesse a fim de emitir uma resposta adequada. $O$ autor relata ainda que ao dirigir o condutor realiza uma discriminação entre os estímulos visuais e os auditivos, sendo que a falta desta discriminação pode ocasionar um ato imprudente $e$ consequentemente um acidente de trânsito.

Além de considerar os processos cognitivos, há de se considerar o contexto em que 0 indivíduo se encontra e como 0 percebe, o que pode ser denominado como qualidade de vida que, segundo a Organização Mundial da Saúde (OMS, 
1998) é a forma como o sujeito percebe sua posição diante do contexto, cultura e sistema nos quais vive em relação aos seus objetivos e expectativas. A OMS propõe 24 facetas da qualidade de vida, agrupadas em 6 domínios, à saber, físico, psicológico, nível de independência, relações sociais, meio ambiente e aspectos espirituais, religião e crenças pessoais. A qualidade de vida está intimamente ligada à maneira como cada um escolhe para viver, ou seja, é uma opção pessoal feita diante dos acontecimentos cotidianos.

Para Takayanagui e Kluthcovsky (2007) o termo é de difícil conceituação, mas geralmente converge para aspectos ligados com à satisfação, qualidade dos relacionamentos, realização pessoal, percepção de bem estar, felicidade, acesso a eventos culturais, lazer, solidariedade e liberdade. De acordo com Chiavenato (1999), o termo possui inúmeras e distintas abordagens e é bastante discutido e pesquisado atualmente. $\mathrm{O}$ autor acrescenta que a qualidade de vida é uma ciência comportamental que trata especificamente, de aspectos ligados ao bem estar das pessoas em situação de trabalho que se reflete de maneira decisiva na qualidade de vida do trabalhador. Por condições favoráveis à vida é possível citar a garantia de alimentação, saúde, educação, trabalho, segurança, esporte, habitação, meio ambiente, saneamento básico, cultura e participação efetiva no processo social.

O termo qualidade de vida tem sido utilizado para avaliar as condições da vida urbana, como transporte, saneamento básico, lazer, segurança, saúde física, conforto e bens materiais. Pode ser ainda definida por alguns aspectos tidos como subjetivos, à saber, concretização de sonhos, harmonia, amar e ser amado, realização no trabalho, respeitar o outro, sentir-se útil, trabalho e lazer equilibrados entre outros. Nota-se que é um conceito amplo ligado à cultura, expectativa de vida, objetivos, padrões e preocupações afetando de modo complexo a saúde física, psicológico e as relações sociais. Os principais fatores que configuram a qualidade de vida no trabalho dizem respeito à renda capaz de satisfazer necessidades pessoais e sociais, orgulho pelo trabalho realizado, vida emocional satisfatória, autoestima, horários e condições de trabalhos sensatos, oportunidades e perspectivas de sucesso na carreira e respeito aos direitos (Papalia e Olds, 2000). Os autores relatam ainda que, a qualidade de vida afeta atitudes e comportamentos importantes para a produtividade individual e grupal, tais como motivação, adaptação à mudanças, criatividade e inovações, criando um conjunto harmonioso e equilibrado de realizações em todos os níveis, como saúde, trabalho, lazer, família e desenvolvimento espiritual. Concluem afirmando que está vinculada à percepções pessoais como sensação de bem estar, que é proporcionada por condições objetivas como renda, emprego, bens possuídos, qualidade de moradia e por condições subjetivas segurança privacidade, reconhecimento e afeto.

No que se refere aos motociclistas, Almeida (2006) salienta que para melhorar a qualidade de vida deste grupo é preciso que eles tomem consciência sobre seus hábitos na vida como realizar exercícios físicos e ter fontes de relaxamento, acordar cedo, aproveitar de forma mais útil sua hora de almoço cuidando mais de si. A alimentação é um fator importante, pois relaciona-se diretamente com a saúde, sendo que uma boa alimentação acaba por manter 0 equilíbrio e a saúde do corpo. É notório que a qualidade do sono que o indivíduo tem durante a noite também relaciona-se à qualidade de vida, permitindo a recuperação de dias intensos de trabalho melhorando 0 rendimento no dia a dia. A tensão no trânsito é algo comum atualmente fazendo parte do cotidiano de motoristas e motociclistas. Para se evitar esse problema é preciso que motoristas e pilotos façam 
alongamentos e exercícios diários protegendo a região cervical. Hidroginástica, acupuntura, massagem e ioga podem auxiliar na diminuição destes fatores (Almeida, 2006).

Este estudo tem como objetivo verificar se existem diferenças entre motociclistas e motoboys no que se refere à atenção concentrada e difusa e qualidade de vida. Para alcançar este objetivo foram utilizados os testes AC, TADIM e o Questionário WHOQOL (qualidade de vida).

\section{MÉTODO}

\section{Participantes}

Participaram do estudo 30 sujeitos, sendo 15 do grupo de motoboys e 15 de motociclistas. Entre os motoboys, todos eram homens e com idades entre 21 e 39 anos $(M=27 ; \quad D P=5,9)$. O nível de escolaridade desses variou de fundamental a superior com a maioria com ensino médio (60\%). Já os motociclistas tiveram idades entre 23 e 63 anos $(M=39 ; D P=11,11)$ e nível de escolaridade médio e superior, com a maioria no ensino médio $(73,3 \%)$.

Os sujeitos foram selecionados aleatoriamente em uma clínica de avaliação psicológica na situação de exame psicotécnico obrigatório para retirada de carteira nacional de habilitação para motoristas no Brasil. As avaliações aconteciam em salas (consultórios) dentro da própria clínica e ocorreram de forma individual durante a entrevista. Os participantes foram avaliados de manhã ou tarde mas nunca de noite e as salas eram silenciosas e com uma quantidade reduzida de estímulos visando a padronização e controle da situação de testagem.

\section{Instrumentos}

Teste de Atenção Concentrada- AC (Cambraia, 2004). O Teste de Atenção Concentrada-AC, visa verificar a rapidez e a exatidão das reações emitidas ao executar tarefas e consiste em 21 linhas contendo 21 símbolos cada, perfazendo um total de 441. A tarefa a ser desempenhada é de cancelar em cada linha horizontal, 7 símbolos, de acordo com um modelo. É solicitado ao candidato que trabalhe sempre da esquerda para a direita e marque com um traço vertical ou oblíquo, todos os símbolos iguais ao modelo, lembrando que apenas deverá passar para a linha seguinte após ter marcado todos os símbolos da anterior. O tempo para a execução deste teste é de 5 minutos, sendo que durante esse tempo deve-se marcar 0 máximo de símbolos possíveis. A correção é feita com o auxílio de um crivo verificando o total de acertos, erros e omissões. Os erros e omissões deverão ser subtraídos uma única vez do total de acertos para se encontrar um total de pontos. Posteriormente, deve-se buscar na tabela percentil, disponível no manual do teste, 0 valor correspondente ao desempenho do candidato. A atenção concentrada pode ser classificada como inferior, mediana ou superior de acordo com o número de pontos e o grau de escolaridade do indivíduo.

Teste de Atenção Difusa - TADIM (Tonglet, 2002).O TADIM, destina-se à observar a rapidez ou a lentidão com que o motorista utiliza sua atenção difusa e classificá-lo de forma padronizada. Consiste em 50 placas coloridas de demarcação quilométricas numeradas de 01 a 50 que estão dispersas espacialmente. É solicitado ao candidato que risque as placas com uma linha inclinada, começando pela placa $\mathrm{n}^{01} \mathrm{e}$ assim na sequência 02 e 03 sucessivamente até chegar à de número 50 , o mais rápido possível durante o tempo de 4 minutos. A correção é feita com o auxílio de um crivo que permite a verificação da ocorrência de omissões ao realizar a sequência solicitada. $\mathrm{O}$ resultado bruto será igual ao número da última placa anotada subtraindo as omissões. De posse do total de pontos, deve-se consultar a tabela de percentil de acordo com a escolaridade a fim de verificar o desempenho da atenção difusa do candidato. 
Questionário Whogol. Este questionário foi criado diante da necessidade de um instrumento eficaz e rápido para avaliação da qualidade de vida, sobre como 0 indivíduo se sente em relação a si mesmo. Ele é composto de 26 questões, divididos em 4 domínios a saber, físico, psicológico, ambiente e as relações interpessoais do sujeito. As respostas são dispostas em uma escala likert de 5 ponto. Caso o participante não tenha certeza sobre que resposta dar em uma questão, deverá escolher entre as alternativas a que the pareça mais apropriada, que muitas vezes, poderá ser a primeira escolha realizada. Com a utilização de uma sintaxe do Whogol, é possível calcular cada domínio de qualidade de vida. Para a correção houve alteração nas pontuações das questões 3, 4 e 26.

\section{RESULTADOS}

Os resultados da Tabela 1apresenta as estatísticas descritivas para os testes estudados. Por esses dados, evidencia-se que as distribuições das pontuações dos testes não apresentam desvios à normalidade em ambos os grupos com exceção da medida bruta do AC. Apesar disso, por se tratar de amostras pequenas, as análises inferenciais foram nãoparamétricas. Observa-se também que houveram pessoas com alta incidência das variáveis em questão em ambas as amostras, mas que os motociclistas apresentaram uma tendência a serem mais atentos e a terem uma melhor qualidade de vida relatada, no geral. De fato, a classificação do AC, indicou que $40 \%$ dos motoboys apresentaram nível médio de atenção concentrada, enquanto nos motociclistas 33,3\% apresentaram nível superior, não havendo motoboys nesse nível em atenção concentrada. Quanto ao TADIM, somente $20 \%$ dos motoboys alcançou classificação superior, enquanto $33,3 \%$ dos motociclistas chegaram a esse nível.

Procurou-se testar, pela análise de Mann Whitney de comparação das medianas das medidas se essas diferenças seriam significativas. Os resultados dessa análise estão na Tabela 2. Por esses resultados observa-se que somente a medida do AC diferenciou os grupos significativamente, sugerindo que os motociclistas apresentaram maiores notas de atenção concentrada em comparação aos motoboys.

TABELA 1.

Estatísticas descritivas do AC e TADIM para a amostra toda.

\begin{tabular}{lrrrrrrrrr}
\hline & $\begin{array}{c}\text { Pontos } \\
\text { AC }\end{array}$ & $\begin{array}{c}\text { Percentil } \\
\text { AC }\end{array}$ & $\begin{array}{r}\text { Pontos } \\
\text { TADIM }\end{array}$ & $\begin{array}{r}\text { Percentil } \\
\text { TADIM }\end{array}$ & $\begin{array}{l}\text { Q. V. } \\
\text { Total }\end{array}$ & $\begin{array}{r}\text { Q. V. } \\
\text { Físico }\end{array}$ & $\begin{array}{r}\text { Q.V. } \\
\text { Psicológico }\end{array}$ & $\begin{array}{c}\text { Q. V. } \\
\text { Ambiente }\end{array}$ & $\begin{array}{c}\text { Q. V. } \\
\text { Relações } \\
\text { interpessoais }\end{array}$ \\
\hline Média & 63,60 & 25,47 & 30,80 & 20,67 & 15,33 & 73,46 & 77,08 & 73,80 & 61,16 \\
Mediana & 64,00 & 20,00 & 30,00 & 10,00 & 16,00 & 73,21 & 75,00 & 75,00 & 57,81 \\
Desvio Padrão & 18,26 & 17,36 & 7,70 & 19,07 & 2,09 & 11,69 & 10,30 & 19,84 & 18,12 \\
Skewness &,- 441 &, 508 &, 135 &, 897 &, 352 &,- 597 &, 427 &,- 162 &, 198 \\
Curtose &,- 211 &,- 093 &,- 768 &,- 778 &, 730 &, 188 &,- 860 & $-1,409$ & $-1,393$ \\
Mínimo & 29 & 1 & 18 & 5 & 12,00 & 50,00 & 62,50 & 41,67 & 37,50 \\
Máximo & 91 & 60 & 43 & 55 & 20,00 & 89,29 & 95,83 & 100,00 & 87,50 \\
\hline
\end{tabular}


DÉBORA SPRENGER - ELIENE COSTA - ANDRÉA BORGES - FERNANDO PESSOTO •

JOSÉ M. MONTIEL・DANIEL BARTHOLOMEU・DANIEL HEITOR・LESLIE LITANO TEALDI

TABELA 2.

Estatísticas para a comparação das medidas efetuadas nos grupos- (1-boy / 2-motociclista) $=1$ e 2 .

\begin{tabular}{|c|c|c|c|c|c|}
\hline $\begin{array}{c}\text { Testes/grupo } \\
\text { (1-boy / 2-motociclista) }\end{array}$ & & $\mathrm{N}$ & $\begin{array}{l}\text { Média } \\
\text { dos } \\
\text { Postos }\end{array}$ & U & $p$ \\
\hline Pontos AC & $\begin{array}{l}1 \\
2\end{array}$ & & $\begin{array}{l}10,33 \\
20,67\end{array}$ & 35 & 0,001 \\
\hline Percentil AC & & $\begin{array}{l}15 \\
15\end{array}$ & $\begin{array}{l}10,40 \\
20,60\end{array}$ & 36 & 0,001 \\
\hline Percentil TADIM & $\begin{array}{l}1 \\
2\end{array}$ & $\begin{array}{l}15 \\
15\end{array}$ & $\begin{array}{l}14,73 \\
16,27\end{array}$ & 101 & 0,627 \\
\hline Pontos TADIM & & $\begin{array}{l}15 \\
15\end{array}$ & $\begin{array}{l}13,63 \\
17,37\end{array}$ & 84,5 & 0,244 \\
\hline Q. V. Total & & $\begin{array}{l}15 \\
15\end{array}$ & $\begin{array}{l}13,60 \\
17,40\end{array}$ & 84 & 0,204 \\
\hline Q. V. Físico & $\begin{array}{l}1 \\
2\end{array}$ & $\begin{array}{l}14 \\
15\end{array}$ & $\begin{array}{l}14,50 \\
15,47\end{array}$ & 98 & 0,759 \\
\hline Q.V. Psicológico & $\begin{array}{l}1 \\
2\end{array}$ & $\begin{array}{l}14 \\
15\end{array}$ & $\begin{array}{l}16,04 \\
14,03\end{array}$ & 90,50 & 0,524 \\
\hline Q. V. Ambiente & $\begin{array}{l}1 \\
2\end{array}$ & $\begin{array}{l}14 \\
15\end{array}$ & $\begin{array}{l}14,36 \\
15,60\end{array}$ & 96 & 0,691 \\
\hline Q. V. Relações interpessoais & $\begin{array}{l}1 \\
2\end{array}$ & $\begin{array}{l}14 \\
15\end{array}$ & $\begin{array}{l}14,54 \\
15,43\end{array}$ & 98,5 & 0,776 \\
\hline
\end{tabular}

\section{DISCUSSÃO}

Segundo Grisci, Scalco e Tanovik (2007) os motoboys geralmente são do sexo masculino, e utilizam a moto para prover seu sustento. Evidenciou-se este fato durante a pesquisa realizada, em que todos eram do sexo masculino, com média da idade de 27 anos, sendo que aproximadamente $93 \%$ deles possuem 0 segundo grau completo, observando que não há distinção de escolaridade significante entre os grupos avaliados. Segundo uma pesquisa da Secretaria Municipal de Jundiaí, no ano de 2006, dos acidentes com óbitos, 28 envolviam moto, 18 vítimas tinham de 20 à 29 anos; 27 dos óbitos foram do sexo masculino e apenas 1 do sexo feminino.

De acordo com Rozestraten (1988) o trânsito é composto de três vertentes, via, homem e veículo, sendo que elas são as principais causas dos acidentes no trânsito.
0 fator homem foi o principal foco nessa pesquisa. Foi analisado que os motoboys apresentaram uma divergência relevante no teste de atenção concentrada com relação aos motociclistas, sendo que $60 \%$ apresentaram resultado inferior ao item avaliado. Com relação ao teste de atenção difusa, TADIM, aproximadamente $67 \%$ dos motoboys obtiveram classificação inferior, já os motociclistas obtiveram pontuação média. Dessa forma observou-se que essa diferença pode ser justificada devido ao fato dos motoboys estarem expostos a um ambiente com diversas contingências, ou seja, geralmente preocupam-se com 0 tempo de entrega, o fator climático do dia, maior exposição a um trânsito agitado, a via pública, instrumento de trabalho, a moto, com o qual garante seu sustento, entre outros fatores que podem estar relacionados à capacidade de concentrar-se em uma única tarefa, justificando assim o aumento relevante no número de acidentes envolvendo motoboys. Por outro lado, os 
motociclistas apresentaram resultados medianos em ambos os testes, um fator que talvez explique tais resultados, é o fato da finalidade do veículo não ser para 0 sustento, e sim para a locomoção e muitas vezes para o passeio.

Nesta pesquisa não foi analisado 0 índice de acidentes dos motoboys e motociclistas participantes, focou-se apenas os fatores que podem estar relacionado às causas acidentes de trânsito. Pode-se concluir, portanto que a agitação do trabalho do motoboy, a atenção distribuída em vários fatores, a baixa atenção concentrada, podem estar ligadas à incidência e reincidência dos acidentes de trânsito envolvendo motoboys. 0 ambiente de trabalho deste profissional é um objeto de estudo que cada vez mais atrai pesquisadores pelo fato de se evidenciar 0 contexto que os envolvem.

\section{CONSIDERAÇÕES FINAIS}

O presente trabalho teve como objetivo verificar possíveis diferenças de aspectos psicológicos entre motociclistas e motoboys, ou seja, condutores de motocicletas que diferem justamente no que diz respeito à utilidade e representação da motocicleta, sendo que estes a utilizam como meio de sustento, enquanto aqueles, para o lazer. Os resultados apontaram diferença significativa na atenção concentrada, indicando que os motociclistas apresentam melhor desempenho neste construto.

Contudo deve-se levar em consideração que outros construtos podem estar relacionados a uma possível diferença significativa entre os grupos e ainda estar ligadas aos processos atencionais e à qualidade de vida, como os fatores da personalidade. Estudos que contemplem estes fatores podem contribuir para possíveis inferências no que diz respeito a este grupo de pessoas, já que podem ainda estar ligados à própria representação da moto enquanto instrumento de trabalho e não apenas um meio de transporte e lazer.

\section{REFERENCIAS}

Almeida, E. P. de. (2006). Cuidando do corpo. Disponivel em: http://www.100km.com.br/blogdomb/?p=19 $\underline{6}$

Bartholomeu, D. (2008). Traços de personalidade e comportamentos de risco no trânsito: um estudo correlacional.Psicol. Argum. 26(54), 193-206.

Bauman, Z. (2003). Comunidade: a Busca por Segurança no Mundo Atual. Rio de Janeiro: Jorge Zahar.

Brasil. Conselho Nacional de Trânsito CONTRAN. (2007). Manual de sinalização de trânsito. vol. I - Sinalização vertical de regulamentação; Brasilia.

Brouwer, W. H., Rothengatter, T.A. \& Van Wolffelaar, P.C. (1988). Compensatory potential in ederly drivers. Em J.A. Rothengatter \& R.A. de Bruin (Eds.), Road user behaviour: theory and research (pp. 48-65). Assen: Van Gorcum.

Botticher, A. \& Van der Molen, H.H. (1988). Predicting overtaking behaviour on the basis of the hierarchical risk model for traffic participants. Em J.A. Rothengatter \& R.A. de Bruin (Eds.), Road user behaviour: theory and research (pp. 48-65). Assen: Van Gorcum.

Cambraia, S. V. (2004). Teste de Atenção Concentrada. São Paulo: Vetor Editora Psicopedagógica Ltda.

Cereser, R. F. (2001). Manual Trânsito em Transe. 3 ed. Vivatrans; Jundiaí.

Chiavenato, I. (1999). Gestão de pessoas: o novo papel dos recursos humanos nas organizações. Rio de Janeiro: Campus.

Brasil (2009). DETRAN. Disponível em www.detran.gov.br acesso em: 28/05/2009. 
Frankenhaeuser, M \& Gardell, B. (1976). Overload and underload in working: outline a multidisciplinary approach. Journal of Human Stress, 2, 35-46.

Honoré, C. (2005). Devagar. São Paulo: Record. Kalimo, R. I(1980). Stress in work: conceptual analysis and a study on prison personnel. Scandinavian Journal of Work, Environment \& Health, 6(3), 1-148.

Levi, L. Las enfermedades psicosomáticas como consecuencia del estrés profesional. Em: Kalimo, R.; El Batawi, M, A.; Cooper, C. L. Los factores psicosociales en el trabajo y su relación con la Salud. Organización Mundial de la Salud: Genebra, 43-50.

Negri, A. e Lazzarato, M. (2001). Trabalho Imaterial: Formas de Vida e Produção de Subjetividade. Rio de Janeiro: DP\&A.

Machado, A.P. (1994). 0 idoso e o trânsito. Monografía de Especialização. Universidade Católica do Paraná.

Michon, D. (1989). Explanatory pitfalls and rulebased driver models. Accident Analysis \& Prevention, 21(4), 341-353.

Ministério do Trabalho e do Emprego (2002). Código Brasileiro de Ocupação. [on-line]. Disponível em http://www.mtecbo.gov.br/cbosite/pages/do wnloads.jsf

Papalia, D. E. \& Olds, S. W. (2000). Desenvolvimento Humano. (trad. Daniel Bueno); 7.ed. Porto Alegre: Artes Médicas Sul.

Rozestraten, R.J.A. (1993). Envelhecimento, mobilidade e participação no trânsito. Em: A. L. Neri (org.). Qualidade de vida e idade madura. Campinas: Papirus, 157-189.

Rozestraten, R. J A. (1998). Psicologia do Transito: Conceitos e processos básicos. EPU - Editora Pedagógica e Universitária Ltda; São Paulo.

Summala, H. (1988). Risk control is not risk adjustment: the zero-risk theory of driver behaviour and its implications. Ergonomics, 31 (4), 491-506.

Tonglet, E. C. (2002) Bateria de Funções Mentais para Motoristas: testes de atenção (BFM-1) 2 Ed. São Paulo: Vetor.

Sabey, B. E. \& Staughton, G. C. (1975). Interacting roles of road environment, vehicle and road users in accidents (pp. 370-386). Em: Manuscrito apresentado na 5 International Conference of the
International Association for Accident and Traffic Medicine. Londres.

Sato, L.; Bernardo, M. (2005). Saúde Mental e Trabalho: os problemas que persistem. Ciência \& Saúde Coletiva 10(4), 869-878.

Glina, D. M. R.; Rocha, L. E.; Batista, M. L.; Mendonça, M. G. V. (2001). Saúde Mental e Trabalho:uma reflexão sobre o nexo com trabalho e o diagnóstico. Rio de Janeiro: Cad. Saúde Pública.

Grisci, C. L. I.; Scalco, P. D. \& Janovik, M. S. (2007). Modos de trabalhar e de ser de motoboys:a vivência espaço-temporal contemporânea. Psicol. cienc. Prof, 27(3), 446-461.

Silva, D. W.; Andrade, S. M.; Soares, D. A.; Nunes, E. de F. \& Melchior, R. (2008) Condições de Trabalho e riscos no trânsito urbano na ótica de trabalhadores motociclistas. Rio de Janeiro: Physis.

Moraes, T. D. (2008). Fatores de risco de acidentes na atividade dos motoboys: limites das análises quantitativas. Revista de Gestão Integrada em Saúde do Trabalho e Meio Ambiente, 3(3), 1-29.

Hoffmann, M. H. (2005). Comportamento do condutor e fenômenos psicológicos. Psicologia: Pesquisa e Trânsito, 1(1), 1724.

Orsati, F. T.; Machado, F. S. ; Kitayama, M. M. G. \& Bruscato, W. L. (2004). Estudo da população fraturada, devido a acidentes de trânsito, internada na Santa Casa de São Paulo. Psicologia Hospitalar , 2(2). [online] Disponível em: http://pepsic.bvsalud.org/scielo.php?script= sci_arttext\&pid=\$16777409200400020000 8\&lng=pt\&nrm=iso. ISSN 1677-7409.

Panichi, R. M. D. \& Wagner, A. (2006). Comportamento de risco no trânsito: revisando a literatura sobre as variáveis preditoras na condução perigosa na população juvenil Interamerican Journal of Psychology, 40(2), 159-166.

Takayanagui, A \& Kluthcovsky. A (2207) Qualidade de vida - Aspectos Conceituais. Revista Salus-Guarapuava PR, Jan/Jun. 2007. Disponivel em: http://www.bvspsi.org.br. Acesso em: 20 nov 2009

Organização Mundial de Saúde (1998). Conceito sobre qualidade de vida 1998 disponível em: http://www.ufrgs.br/psiq/whogol1.html\#1 Acesso em: 20 nov 2009 